\title{
Cost-Effectiveness of IDegLira Versus Insulin Intensification Regimens for the Treatment of Adults with Type 2 Diabetes in the Czech Republic
}

\author{
Milan Kvapil • Martin Prázný • Pavel Holik · Karel Rychna • \\ Barnaby Hunt
}

Received: August 21, 2017 / Published online: October 23, 2017

(C) The Author(s) 2017. This article is an open access publication

\section{ABSTRACT}

Introduction: The aim of this study was to evaluate the long-term cost-effectiveness of the insulin degludec/liraglutide combination (IDegLira) versus basal insulin intensification strategies for patients with type 2 diabetes mellitus (T2DM) not optimally controlled on basal insulin in the Czech Republic.

Methods: Cost-effectiveness was evaluated using the QuintilesIMS Health CORE Diabetes model, an interactive internet-based model that

Enhanced Content To view enhanced content for this article go to http://www.medengine.com/Redeem/ C4CCF060389DCE69.

Electronic supplementary material The online version of this article (doi:10.1007/s13300-017-0323-y) contains supplementary material, which is available to authorized users.

M. Kvapil

Department of Internal Medicine, Faculty Hospital Motol, Prague, Czech Republic

M. Prázný

Third Internal Clinic, Clinic of Endocrinology and Metabolism, General University Hospital, Prague, Czech Republic

P. Holik $(\bowtie) \cdot$ K. Rychna

Novo Nordisk s.r.o, Prague, Czech Republic

e-mail: pavh@novonordisk.com

B. Hunt

Ossian Health Economics and Communications,

Basel, Switzerland simulates clinical outcomes and costs for cohorts of patients with diabetes. The analysis was conducted from the perspective of the Czech Republic public payer. Sensitivity analyses were conducted to explore the sensitivity of the model to plausible variations in key parameters.

Results: The use of IDegLira was associated with an improvement in the quality-adjusted life expectancy of 0.31 quality-adjusted life-years (QALYs), at an additional cost of Czech Koruna (CZK) 107,829 over a patient's lifetime compared with basal-bolus therapy, generating an incremental cost-effectiveness ratio (ICER) of CZK 345,052 per QALY gained. In a scenario analysis, IDegLira was associated with an ICER of CZK 693,763 per QALY gained compared to basal insulin + glucagon-like peptide-1 receptor agonist (GLP-1 RA). The ICERs are below the generally accepted willingness-to-pay threshold (CZK 1,100,000/QALY gained at the time of this analysis).

Conclusions: Results from this evaluation suggest that IDegLira is a cost-effective treatment option compared with basal-bolus therapy and basal insulin + GLP-1 RA for patients with T2DM in the Czech Republic whose diabetes is not optimally controlled with basal insulin.

Funding: Novo Nordisk.

Keywords: Cost-effectiveness; Fixed-ratio combination therapy; IDegLira; QALY; Type 2 diabetes 


\section{INTRODUCTION}

Diabetes is a chronic metabolic disorder characterized by elevated levels of blood glucose (hyperglycemia). The disease is associated with considerable morbidity and mortality [1] and represents one of the largest challenges to health worldwide. According to the Institute of Health Information and Statistics of the Czech Republic (UZIS), there were 862,882 people with diagnosed diabetes in the Czech Republic in 2015 (excluding those with impaired glucose tolerance) [2], of whom $91.4 \%$ had type 2 diabetes mellitus (T2DM), 6.5\% had type 1 diabetes mellitus (T1DM), and the remainder had secondary diabetes [2].

T2DM is characterized by insulin resistance (decreased tissue response to insulin) and a progressive loss of $\beta$-cell function, ultimately resulting in insulin deficiency [3]. T2DM is more common in obese adults over 40 years of age, although it is becoming more common in children and adolescents due to increased obesity rates in these groups [4].

The long-term complications of diabetes, which are a consequence of prolonged hyperglycemia, include retinopathy, nephropathy, neuropathy, and cardiovascular disease [1]. A study of patient records of people with T2DM $(n=495)$ in the Czech Republic found that 44.2 and $49.3 \%$ of patients had at least one macrovascular complication and at least one microvascular complication, respectively, and that $82.8 \%$ of all patients were being treated with anti-hypertensive medications [5]. In 2015 there were 29,000 diabetes-related deaths $(2.7$ deaths per 1000 population) in the Czech Republic [2].

The treatment of diabetes and its associated complications imposes an immense economic burden on national healthcare systems. In the Czech Republic the mean diabetes-related expenditure per patient with diabetes was estimated to be around EUR $1445.16^{1}$ in 2015 [6].

The clinical goal in the treatment of diabetes is to achieve good glycemic control with minimal hypoglycemia or other adverse effects of

\footnotetext{
$\overline{1}$ Converted from USD using currency converter http:// www.xe.com/currencyconverter, January 2017.
}

treatment, such as weight gain. International guidance recommends a glycated hemoglobin $\left(\mathrm{HbA}_{1 \mathrm{c}}\right)$ target of $<7 \%(53.0 \mathrm{mmol} / \mathrm{mol})$ [7]. T2DM is a progressive disease [8], and treatment is intensified over time. Most patients with T2DM will eventually require insulin to maintain target $\mathrm{HbA}_{1 \mathrm{c}}$ levels, and many patients will need to intensify their insulin regimen as the disease continues to progress [7]. Guidance in the Czech Republic for the treatment of T2DM is in line with American Diabetes Association (ADA) and European guidance [7, 9]. Common strategies for intensification of insulin therapy are (1) to titrate the basal insulin further, (2) to add bolus insulin, (3) to switch to premix insulin, or (4) to add a glucagon-like peptide-1 (GLP-1) receptor agonist (RA) to the insulin therapeutic regimen. In the Czech Republic guidance, therapy with a fixed combination of GLP-1 receptor agonist and basal insulin and with GLP-1 RA and basal insulin are both recommended [10].

Despite clear guidelines and the availability of many different treatment options, glycemic control remains suboptimal in a substantial number of patients [11, 12]. In a European study, the overall proportion of patients with T2DM not achieving good glycemic control was $37 \%$, rising to $64 \%$ when only patients receiving insulin/injectables were considered [13]. An expert survey by IMS Health Technology Solutions Czech Republic s.r.o. found that $53 \%$ of patients on basal insulin in the Czech Republic do not have adequate glycemic control $\left[\mathrm{HbA}_{1 \mathrm{c}} \geq 60 \mathrm{mmol} / \mathrm{mol}(7.6 \%)\right]$. Barriers to intensification of insulin therapy and good glycemic control in these patients include hypoglycemia, weight gain, and complex treatment regimens [14-18].

IDegLira is a once-daily, fixed-ratio combination of the long-acting basal insulin analog (insulin degludec; IDeg) and the GLP-1 RA (liraglutide) administered in a single pen injection device. It was developed to take advantage of the combined effects of IDeg and liraglutide on glycemic control through their complementary mechanisms of action. IDegLira is indicated for the treatment of adults with T2DM to improve glycemic control in combination with oral glucose-lowering medicinal products when these 
alone or combined with a GLP-1 RA or basal insulin do not provide adequate glycemic control [19]. A suggested place in the T2DM treatment pathway for IDegLira is when these patients are uncontrolled on basal insulin and require treatment intensification.

Two phase 3 DUAL $^{\mathrm{TM}}$ (Dual Action of Liraglutide and Insulin Degludec in Type 2 Diabetes) trials provide the core efficacy and safety evidence for IDegLira in patients with T2DM uncontrolled on basal insulin. The DUAL II trial (NCT 01392573; IDegLira vs. IDeg) found that at equivalent insulin doses IDegLira was superior to IDeg in terms of lowering $\mathrm{HbA}_{1 \mathrm{c}}$ and was significantly more favorable in terms of changes in body weight (weight loss with IDegLira vs. no weight change with IDeg) [20]. The results also confirmed that hypoglycemia was numerically lower with IDegLira versus IDeg [20]. The DUAL V trial [NCT 01952145; IDegLira vs. up-titration of insulin glargine U100 (IGlar U100; Lantus $\left.{ }^{\circledR}\right)$ ], which enrolled patients with T2DM uncontrolled on IGlar U100 at trial entry, found that IDegLira was superior to IGlar $\mathrm{U} 100$ in terms of lowering $\mathrm{HbA}_{1 \mathrm{c}}$, change in body weight (weight loss with IDegLira vs. weight gain with IGlar U100), and hypoglycemia [21]. Despite a superior reduction in $\mathrm{HbA}_{1 \mathrm{c}}$ the rate of confirmed hypoglycemia was 57\% lower with IDegLira [21].

At the time of data analysis (February 2016) there were no head-to-head clinical trials of IDegLira versus other treatment options for intensification of basal insulin therapy. However, an indirect statistical comparison (pooled multivariable analysis) was conducted to establish an estimate of the treatment effects of IDegLira versus basal-bolus insulin therapy and liraglutide added to basal insulin in patients with T2DM uncontrolled on basal insulin [22]. The pooled analysis showed that IDegLira was associated with a significantly greater decrease in $\mathrm{HbA}_{1 \mathrm{c}}$ versus both basal-bolus therapy and GLP-1 RA added to basal insulin, with lower hypoglycemia rates and a greater reduction in weight versus basal-bolus therapy [22]

In the current environment of cost containment, decision-making based on both clinical and economic evidence is paramount for optimum resource use and service delivery for patients with T2DM. Cost-effectiveness analyses are increasingly used to inform pharmaceutical reimbursement and/or pricing decisions in many countries. Such analyses help decision-makers determine whether the health benefits associated with adopting the novel treatment are worth the cost, compared with existing therapies. The objective of the study reported here was to evaluate the long-term cost-effectiveness of IDegLira versus basal-bolus insulin therapy, as an alternative insulin intensification strategy, in adult patients with type 2 diabetes not optimally controlled on basal insulin in the Czech Republic. The cost-effectiveness of IDegLira versus GLP-1 RA added to basal insulin was investigated in a scenario analysis.

\section{METHODS}

\section{Type of Economic Analysis}

A cost-effectiveness analysis was conducted to estimate the difference in cost between IDegLira and a comparator, divided by the difference in health effects. A generally accepted effectiveness measure used in cost-effectiveness analyses is the quality-adjusted life-year (QALY). A QALY is an overall measure of health as a combination of the duration of life and the health-related quality of life [23]. The outcome measure is termed an incremental cost-effectiveness ratio (ICER):

$$
\text { ICER }=\frac{\text { Cost }_{\text {IDegLira }}-\text { Cost }_{\text {comparator }}}{\text { Effect }_{\text {IDegLira }}-\text { Effect }_{\text {comparator }}} .
$$

Therefore, the cost-effectiveness (the ICER) was expressed as the cost/QALY gained. An intervention is considered to be cost-effective if the ICER falls below a defined willingness-to-pay (WTP) threshold. In the Czech Republic there is no official guidance on the WTP threshold, but the SÚKL ${ }^{2}$ (State Institute for Drug Control) applies a "generally accepted threshold" based on threefold the gross domestic product per capita in all administrative proceedings [24]. At the time of

\footnotetext{
2 Státní ústav pro kontrolu léčiv.
} 
this analysis this was 1,100,000 CZK/QALY gained.

\section{Choice of Comparators}

In the Czech Republic the most relevant comparator for IDegLira was considered to be basal-bolus therapy, such as, for example, the addition of insulin aspart to insulin glargine three times daily (IGlar $+3 \times$ IAsp). During the administrative reimbursement procedure for IDegLira, SÚKL confirmed that basal-bolus therapy was the only appropriate comparator treatment. The combination of basal insulin and GLP-1 RA could not be considered as it is not reimbursed in the Czech Republic [25]. Therefore, IDegLira versus basal-bolus therapy formed the base case analysis, which was conducted in February 2016. However, as the combination of basal insulin and GLP-1 RA has been included in the recent guidance in the Czech Republic, we investigated this treatment option in an alternative scenario analysis. This analysis was requested by the General Insurance Company of Czech Republic (a healthcare payer) during negotiations that followed the positive Evaluation Report from the SÚKL, and it was conducted in May 2016. The Evaluation Report was issued by SÚKL before the Final Decision to guarantee the participants the right to comment and raise possible objections and provide counter-arguments, thereby ensuring the transparency and fairness of the administrative proceeding during which price and reimbursement levels and conditions are set. In this process, all administrative proceedings are led by the SÚKL, and the Marketing Authorization Holder and insurance companies (healthcare payers) are participants only. The process is completed with the issue of the Final Decision by SÚKL which describes the assessment and the main reasons for the price and reimbursement decisions.

As there were no head-to-head studies comparing IDegLira with basal-bolus therapy and the combination of basal insulin and GLP-1 RA at the time of evaluation, data to inform the analysis were taken from the expanded pooled analysis [22], which includes data from patients receiving IGlar $\mathrm{U} 100+3 \times$ IAsp or IDeg $+3 \times$ IAsp in the basal-bolus arm $(n=210)$.

\section{Model Overview}

The long-term cost-effectiveness of IDegLira versus relevant comparators was assessed using the QuintilesIMS Health CORE Diabetes model (referred to as the IMS CORE Diabetes model elsewhere in text) and effectiveness data from the expanded pooled analysis. The analysis follows standard methodology as prescribed by the IMS CORE Diabetes model and previously published economic evaluations of IDegLira $[26,27]$.

The IMS CORE Diabetes model is an internet-based, interactive computer model developed to determine the long-term health outcomes and economic consequences of implementing interventions in the treatment of diabetes $[28,29]$. The model allows extrapolation of results from short-term trials to long-term outcomes, and it considers diabetes therapy, oral hypoglycemic medications, screening and treatment strategies for microvascular complications, treatment strategies for end-stage complications, and multifactorial interventions. The following long-term outcomes are evaluated in the model: life expectancy, quality-adjusted life expectancy, cumulative incidence of diabetes-related complications, time to onset of diabetes-related complications, and direct medical costs.

The IMS CORE Diabetes model simulates the complications of diabetes (angina, myocardial infarction, congestive heart failure, stroke, peripheral vascular disease, diabetic retinopathy, macular edema, cataract, hypoglycemia, ketoacidosis, lactic acidosis, nephropathy and end-stage renal disease, neuropathy, foot ulcer, and amputation). It takes data from a number of different sources to perform patient level simulations (Fig. 1). Baseline cohort characteristics are used to define a simulated patient, and treatment effects based on the trial data are applied. Other diabetes management strategies are also included, since these affect the risk of complications. The simulated patient then 


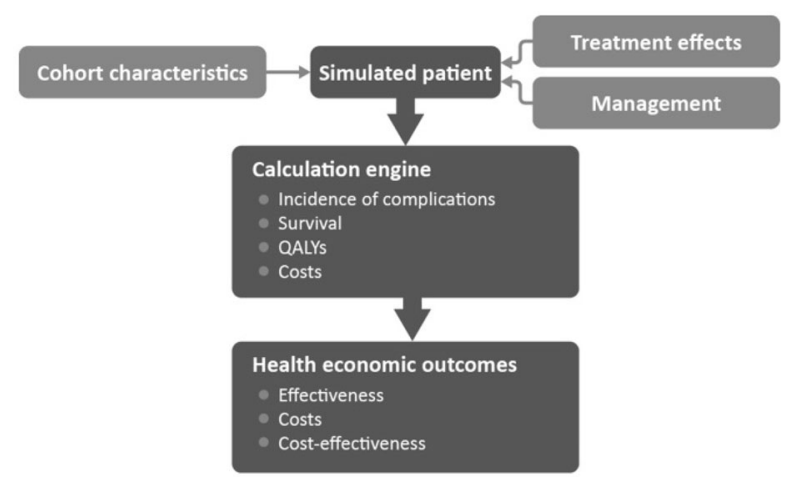

Fig. 1 Performing simulations with the QuintilesIMS Health CORE Diabetes model. QALY Quality-adjusted life year

enters the model, in which clinical events are projected over patient lifetimes. Based on these clinical events and their impact on costs and quality of life, health economic outcomes are projected.

\section{Time Horizon and Treatment Duration}

The base case analysis used a lifetime (50-year) time horizon to capture all relevant long-term complications and associated costs in order to assess their impact on life expectancy and quality-adjusted life expectancy. The impact of shortening the time horizon was explored in sensitivity analyses. The model takes into account mortality as a result of diabetes-related complications and background mortality based on Czech Republic-specific life tables [30]. Therefore, while a 50-year time horizon was used, patients were not assumed to live for 50 years. All patients had died after 50 years of the modeling analysis.

Patients receiving IDegLira were assumed to receive the treatment for the first 5 years of the analysis. After 5 years, treatment was intensified to basal-bolus insulin therapy with once-daily IGlar U100 $+3 \times$ IAsp. This assumption recognizes that intensification to basal-bolus therapy will be required for patients to maintain glycemic control over the long term. Patients in the basal-bolus therapy arm were assumed to remain on this therapy for the duration of their lifetime.

\section{Discounting}

Clinical and cost outcomes were discounted symmetrically at 3\% per annum, which is in line with health economic guidance for the Czech Republic [31].

\section{Clinical Data}

A simulated cohort of patients was defined, with baseline risk factors based on the baseline characteristics of patients randomized to receive IDegLira in the DUAL II study (Table 1). The proportion of patients using tobacco products was based on the DUAL II trial data, but the number of cigarettes smoked per day was assumed to be the same as that calculated for the general Czech Republic population and was based on country-specific data [32]. Similarly, mean weekly alcohol consumption was taken from Czech Republic-specific data for the general population [32].

Treatment effects applied in the first year of the analysis (Table 2) were based on data from the expanded pooled analysis [22].

After the first year of the analysis, systolic blood pressure and serum lipids were assumed to follow the natural progression algorithms built into the CORE Diabetes Model, based on the 30-year UK Prospective Diabetes Study (UKPDS 82) or Framingham data (as described by Palmer et al. [29]). Benefits in terms of $\mathrm{HbA}_{1 \mathrm{c}}$, and body mass index (BMI) were assumed to persist for the 5 years that patients received IDegLira and to be abolished upon treatment switching. Hypoglycemia rates following treatment intensification were based on the basal-bolus arm, with non-severe and severe hypoglycemic event rates of 794.63 and 2.85 events per 100 patient-years, respectively, applied.

\section{Costs and Resource Use}

Costs were estimated from the Czech Republic public payer perspective. Direct costs captured included pharmacy costs, costs associated with diabetes-related complications, and 
Table 1 Baseline cohort characteristics

\begin{tabular}{|c|c|}
\hline Demographics and risk factors & Phase 3 DUAL $^{\mathrm{TM}}$ II trial cohort (patients receiving IDegLira) \\
\hline Start age (years) & $56.8(8.9)$ \\
\hline Duration of diabetes (years) & $10.3(6.0)$ \\
\hline Percentage male & $56.3 \%$ \\
\hline $\mathrm{HbA}_{1 \mathrm{c}}(\%)$ & $8.7(0.7)$ \\
\hline SBP $(\mathrm{mmHg})$ & $132.4(14.8)$ \\
\hline Total cholesterol (mg/dL) & $182.0(45.5)$ \\
\hline HDL cholesterol (mg/dL) & $43.4(11.0)$ \\
\hline LDL cholesterol (mg/dL) & $101.9(37.1)$ \\
\hline Triglycerides $(\mathrm{mg} / \mathrm{dL})$ & $196.8(148.0)$ \\
\hline BMI $\left(\mathrm{kg} / \mathrm{m}^{2}\right)$ & $33.6(5.7)$ \\
\hline Percentage smokers (\%) & 16.1 \\
\hline Cigarettes per day ${ }^{a}$ & 14.44 \\
\hline Alcohol consumption ( $\mathrm{fl} \mathrm{oz} /$ week $)^{\mathrm{b}}$ & 5.01 \\
\hline
\end{tabular}

Values in table are presented as the mean with the standard deviation (SD) in parenthesis

$B M I$ Body mass index, $H b A_{1 c}$ glycated hemoglobin, $H D L$ high-density lipoprotein, IDegLira fixed-ratio combination of the insulin analog degludec (IDeg) and the glucagon-like peptide-1 (GLP-1) receptor agonist (GLP-1 RA) liraglutide, $L D L$ low-density lipoprotein, $S B P$ systolic blood pressure, $S D$ standard deviation

a Source: Sovinova H and Csemy L: The use of tobacco and alcohol in the Czech Republic 2012 [32]

b Derived from [32]

concomitant patient management costs. All costs were expressed in $2016 \mathrm{CZK}^{3}$

Treatment costs were calculated based on the adjusted doses in the expanded pooled analysis from which clinical data on the treatment effects were also taken [22]. One needle was assumed for each injection. Patients were assumed to be receiving metformin in addition to the study medication. Following treatment intensification to basal-bolus therapy, treatment costs were the same in both arms (matched to IGlar U100+3 $\times$ IAsp). Patients receiving IDegLira were assumed to use one self-monitored blood glucose (SMBG) test per day (comprised of one SMBG test strip and one lancet), and patients receiving IGlar $\mathrm{U} 100+3 \times$ IAsp were assumed to use four

\footnotetext{
${ }^{3}$ For context $27 \mathrm{CZK}$ was approximately equivalent to 1 EUR at the time of analysis (http://www.xe.com/ currencyconverter).
}

SMBG tests per day (alternative assumptions around SMBG use were evaluated in sensitivity analyses). The total annual per-patient cost (including drugs, needles, and SMBG testing) was CZK 68,684.14 for IDegLira versus CZK $43,731.35$ for IGlar U100 + $3 \times$ IAsp (based on current prices in February 2016 when the analysis was conducted).

Resource use relating to patient management was assumed to be the same as that for the general population with T2DM in the Czech Republic in all treatment arms. Patient management costs captured in the analysis included concomitant medications (aspirin, statins, and angiotensin-converting enzyme inhibitors), screening for renal disease, retinopathy and diabetic foot complications, and post-complication management (such as intensive insulin treatment after myocardial infarction). The cost of treating diabetes-related complications in the 
Table 2 Treatment effects applied in patients previously uncontrolled on basal insulin (IDegLira vs. basal-bolus therapy)

\begin{tabular}{|c|c|c|}
\hline Parameter & IDegLira & $\begin{array}{l}\text { Basal-bolus } \\
\text { therapy }\end{array}$ \\
\hline $\mathrm{HbA}_{1 \mathrm{c}}(\%)$ & $\begin{array}{r}-1.66 \\
(0.96)\end{array}$ & $\begin{array}{r}-1.33^{*} \\
(0.96)\end{array}$ \\
\hline SBP $(\mathrm{mmHg})$ & $\begin{array}{r}-6.86 \\
(13.20)\end{array}$ & $\begin{array}{r}-0.93^{*} \\
(13.20)\end{array}$ \\
\hline Total cholesterol (mg/dL) & $\begin{array}{r}-10.13 \\
(30.28)\end{array}$ & $\begin{array}{r}+1.50^{*} \\
(30.28)\end{array}$ \\
\hline HDL cholesterol (mg/dL) & $\begin{array}{r}+0.52 \\
(6.79)\end{array}$ & $\begin{array}{r}+0.79 \\
(6.79)\end{array}$ \\
\hline LDL cholesterol $(\mathrm{mg} / \mathrm{dL})$ & $\begin{array}{r}-6.85 \\
(23.83)\end{array}$ & $\begin{array}{r}+0.08^{*} \\
(23.83)\end{array}$ \\
\hline Triglycerides $(\mathrm{mg} / \mathrm{dL})$ & $\begin{array}{r}-25.74 \\
(103.71)\end{array}$ & $\begin{aligned}+ & 3.82^{*} \\
& (103.71)\end{aligned}$ \\
\hline $\operatorname{BMI}\left(\mathrm{kg} / \mathrm{m}^{2}\right)$ & $\begin{array}{r}-1.04 \\
(1.34)\end{array}$ & $\begin{array}{r}+1.38^{*} \\
(1.34)\end{array}$ \\
\hline $\begin{array}{l}\text { Severe hypoglycemia event } \\
\text { rate (events/100 PYE) }\end{array}$ & 0.84 & 2.85 \\
\hline $\begin{array}{l}\text { Non-severe hypoglycemia } \\
\text { event rate (events/100 } \\
\text { PYE) }\end{array}$ & $125.05^{*}$ & $794.63^{*}$ \\
\hline
\end{tabular}

Source: Electronic Supplementary Material appendix of extended pooled analysis by Freemantle et al. [22]

Values in table are presented as the mean with the SD in parenthesis

PYE Patient years of exposure

* Statistically significant difference

year of the event and the annual follow-up costs (applied in each year of the simulation subsequent to the first event) were consistent with previous cost-effectiveness analyses in the Czech Republic [see Electronic Supplementary Material (ESM) Appendix for all patient management costs].

\section{Estimation of Quality-Adjusted Life Expectancy}

Utilities and disutilities (i.e., measures of the impact on quality of life) associated with complications of diabetes were obtained from published sources [29, 33-36]. Quality-adjusted life expectancy was assessed using the additive "CORE Default Method", which involves taking the lowest health state score associated with existing complications and adding event utilities for any events that occur in that year to create annual health state utility scores for each simulated patient [29].

\section{Sensitivity Analyses}

The extrapolation of clinical results by modeling the long-term consequences is associated with uncertainty. Therefore, sensitivity analyses were performed on key parameters in the model to assess the robustness of the base case findings. The following sensitivity analyses were conducted:

- Time Horizon: The influence of time horizon on the outcomes projected by the model was investigated by running analyses over 10 and 20 years. It should be noted that a time horizon of 50 years was required for all modeled patients to have died, and therefore shorter time horizons do not capture all complications and costs.

- Discount Rate: To examine the effect of discounting on cost-effectiveness outcomes, simulations were performed with (symmetric) discount rates of 0 and 5\%.

- Key Drivers of Clinical Benefit: Five simulations were run to assess the key drivers of clinical benefit associated with IDegLira. In the IDegLira arm, changes in $\mathrm{HbA}_{1 \mathrm{c}}$, systolic blood pressure, serum lipids, BMI, and hypoglycemia were set to the value in the IGlar + $3 \times$ IAsp arm in turn. This allowed the contribution of individual clinical effects to long-term health economic outcomes to be assessed.

- Statistically Significant Differences Only: Only the treatment effects that were significantly different between the IDegLira and IGlar $+3 \times$ IAsp arms were applied.

- $\mathrm{HbA}_{1 \mathrm{c}}$ Progression: Two alternative approaches to $\mathrm{HbA}_{1 \mathrm{c}}$ progression were explored. In the first, the UKPDS $\mathrm{HbA}_{1 \mathrm{c}}$ progression equation was applied in both 
arms of the simulation. $\mathrm{HbA}_{1 \mathrm{c}}$ increases over time in both arms of the analysis, with the $\mathrm{HbA}_{1 \mathrm{c}}$ benefit in the IDegLira arm gradually reduced. In the second approach, no $\mathrm{HbA}_{1 \mathrm{c}}$ changes were applied following the treatment effects applied in the first year of the analysis. This attempts to capture the legacy effect, where an early improvement in $\mathrm{HbA}_{1 \mathrm{c}}$ has a benefit in the later years of life, even if the $\mathrm{HbA}_{1 \mathrm{c}}$ difference is abolished.

- Upper and Lower Limit of $\mathrm{HbA}_{1 \mathrm{c}}$ Change: Simulations were run with the upper and lower 95\% confidence interval of the modeled $\mathrm{HbA}_{1 \mathrm{c}}$ change applied in the IDegLira arm. All other parameters in the IDegLira and IGlar $+3 \times$ IAsp arm remained unchanged.

- BMI Progression: The base case analysis assumed that the BMI benefit associated with IDegLira was abolished upon treatment switching, and an alternative to this assumption was explored in a sensitivity analysis, where the difference between the IDegLira and IGlar $+3 \times$ IAsp was maintained for the duration of the analysis.

- Treatment Switching Patterns: To investigate the effect of the timing of treatment switching on cost-effectiveness, simulations were performed, with the year of treatment switch to basal-bolus therapy in the IDegLira arm brought forward to the end of year 3 , pushed back to the end of year 7 , and no treatment switching. In the IGlar $+3 \times$ IAsp arm no treatment switching was assumed to occur, and therefore changes were only applied in the IDegLira arm.

- Application of Alternative Insulin Costs: A scenario was conducted with the price of $\mathrm{NPH}$ insulin (intermediate-acting insulin) applied in the IGlar $+3 \times$ IAsp arm. Conservatively, all other parameters were as per the base case analysis.

- Alternative dosing in the Comparator Arm: Alternative dosing was evaluated in two scenarios. In the first, the defined daily dose of the comparator treatments was applied (IGlar $40 \mathrm{IU}$, IAsp $40 \mathrm{IU}$ ), with IDegLira dosing unchanged from the base case analysis (IDegLira 44.8 dose steps). In the second scenario, the observed trial doses were investigated during the analysis (i.e., doses were not adjusted using the statistical model in this sensitivity analysis). The doses were: IDegLira, 44.8 dose steps; IGlar, 67.6 IU; IAsp, 64.0 IU.

- Alternative Injection and SMBG Frequency in the Comparator Arm: A conservative analysis was conducted which assumed that patients in the IGlar $+3 \times$ IAsp arm used only two needles (for subcutaneous injection) and two SMBG tests per day. No other parameters were changed in this analysis.

- Costs of Complications: The effect of overor under-estimating the direct cost of treating diabetes-related complications was investigated in two scenarios. In the first, the cost of treating complications was increased by $10 \%$, and in the second the cost was reduced by $10 \%$.

- Hypoglycemia Disutilities: The impact of disutilities for severe and non-severe hypoglycemic events on outcomes was assessed by using alternative published values [37].

- Update to the CORE Diabetes Model: In February 2014, an update to the CORE Diabetes Model incorporating data from the UKPDS 82 study was released, and an analysis using this version of the model was run. While a validation study of the revised model has been published, the model proprietors suggest that the update is used in a sensitivity analysis, with the previous version being used in the base case.

- Probabilistic Sensitivity Analysis: Probabilistic sensitivity analysis (PSA) was performed using the predefined function in the CORE Diabetes Model. Cohort characteristics, treatment effects, and complication costs and utilities were sampled from distributions, and the simulation was run using a second order Monte Carlo approach. Cohorts of 1000 patients were run through the model 1000 times for the PSA, as results were not subject to random statistical variation with these settings. 


\section{Scenario Analysis}

A scenario analysis was conducted to compare IDegLira with the combination of GLP-1 RA (liraglutide) added to basal insulin. As in the base case analysis, treatment effects applied in the first year of the analysis (Table 3) were based on data from the expanded pooled analysis [22]. In this scenario, patients receiving both IDegLira and liraglutide added to basal insulin were assumed to receive treatment for the first 5 years of the analysis and then intensify to basal-bolus therapy. On intensification to basal-bolus therapy the benefits in terms of $\mathrm{HbA}_{1 \mathrm{c}}$ and BMI were abolished, and hypoglycemia rates were based on the basal-bolus arm (as described above for the IDegLira treatment arm of the base case analysis).

Patients receiving both IDegLira and liraglutide added to basal insulin were assumed to use one SMBG test per day. The total annual per-patient cost (including drugs, needles, and SMBG testing) was CZK 66,006.10 for IDegLira versus CZK 58,993.81 for liraglutide added to basal insulin (based on current prices in May 2016 when the analysis was conducted). All other parameters in this analysis were unchanged.

\section{Compliance with Ethics Guidelines}

This article is based on previously conducted studies and does not involve any new studies of human or animal subjects performed by any of the authors.

\section{RESULTS}

\section{Base Case Analysis}

Clinical benefits of treatment with IDegLira resulted from both a reduced incidence of diabetes-related complications over the 50-year time horizon of the model and a delayed mean time to onset of diabetes-related complications. Mean time to onset of any diabetes-related complication in the modeling analysis was approximately 0.4 years longer with IDegLira than with IGlar U100 $+3 \times$ IAsp. Benefits were observed across all micro- and macrovascular complications included in the analysis.

IDegLira was associated with increased treatment costs (driven by the acquisition costs over the first 5 years of the analysis), but this was partially offset by cost savings as a result of avoided diabetes-related complications.

Table 3 Treatment effects applied in patients previously uncontrolled on basal insulin (IDegLira vs. liraglutide added to basal insulin)

\begin{tabular}{lll}
\hline Parameter & IDegLira & Liraglutide added to basal insulin \\
\hline $\mathrm{HbA}_{\mathrm{lc}}(\%)$ & $-1.66(0.96)$ & $-1.32^{*}(0.96)$ \\
$\mathrm{SBP}(\mathrm{mmHg})$ & $-6.86(13.20)$ & $-4.67^{*}(13.20)$ \\
Total cholesterol $(\mathrm{mg} / \mathrm{dL})$ & $-10.13(30.28)$ & $-12.66^{*}(30.28)$ \\
$\mathrm{HDL}$ cholesterol $(\mathrm{mg} / \mathrm{dL})$ & $+0.52(6.79)$ & $-0.77(6.79)$ \\
$\mathrm{LDL}$ cholesterol $(\mathrm{mg} / \mathrm{dL})$ & $-6.85(23.83)$ & $-9.07(23.83)$ \\
Triglycerides $(\mathrm{mg} / \mathrm{dL})$ & $-25.74(103.71)$ & $-18.99(103.71)$ \\
$\mathrm{BMI}\left(\mathrm{kg} / \mathrm{m}^{2}\right)$ & $-1.04(1.34)$ & $-1.29^{*}(1.34)$ \\
Severe hypoglycemia event rate $($ events/100 PYE) & 0.84 & $0^{\mathrm{a}}$ \\
Non-severe hypoglycemia event rate (events/100 PYE) & $125.05^{*}$ & 124.46 \\
\hline
\end{tabular}

Values in table are presented as the mean with the SD in parenthesis

* statistically significantly different from IDegLira

a Significance could not be tested as there were zero events 
Table 4 Base case analysis-IDegLira versus basal-bolus therapy

\begin{tabular}{llll}
\hline Parameters & IDegLira & Basal-bolus therapy & Difference \\
\hline Discounted life expectancy (years) & $13.57(0.19)$ & $13.46(0.18)$ & +0.10 \\
Discounted quality-adjusted life expectancy (QALYs) & $8.69(0.12)$ & $8.38(0.12)$ & +0.31 \\
Discounted direct costs (CZK) & $1,037,842(25,466)$ & $930,013(25,147)$ & $+107,829$ \\
ICER (life expectancy) & CZK 1,043,842 per life year gained & \\
ICER (quality-adjusted life expectancy) & CZK 345,052 per QALY gained & \\
\hline
\end{tabular}

Values in table are presented as the mean with the SD in parenthesis

$C Z K$ Czech Koruna, ICER incremental cost-effectiveness ratio, QALY quality-adjusted life year

Treatment with IDegLira was associated with improvements in quality-adjusted life expectancy of 0.31 QALYs, at an additional cost of CZK 107,829 over a patient's lifetime, versus IGlar U100 + $3 \times$ IAsp treatment (Table 4). IDegLira was associated with an ICER of CZK 345,052 per QALY gained versus IGlar $\mathrm{U} 100+3 \times$ IAsp, which falls below the commonly quoted WTP threshold of CZK 1,100,000 per QALY gained; therefore, IDegLira is likely to be considered cost-effective.

\section{One-Way Sensitivity Analysis Results}

Sensitivity analyses found that the outcomes projected in the present analysis were robust to changes in the input parameters and the assumptions used (Fig. 2 and ESM Appendix). IDegLira was likely to be cost-effective in all scenarios investigated, with all ICERs falling under the WTP threshold of CZK 1,100,000 per QALY gained.

Shortening the time horizon of the analysis had a notable impact on the calculated outcomes, with the clinical benefit reduced at 20 and 10 years, primarily due to the improvements in physiological parameters associated with IDegLira reducing the risk of long-term complications. Surprisingly, the increase in cost with IDegLira was smaller over reduced time horizons, likely due to the survival paradox, where greater survival in the IDegLira arm results in greater costs in later years. Shortening the time horizon to 10 years resulted in an ICER of CZK 413,391 per QALY gained.
Altering the discount rates used also reflected the long-term benefits with IDegLira. Reducing the discount rate led to a fall in the ICER to CZK 296,784 per QALY gained, while increasing the discount rate to $5 \%$ had the converse effect.

Abolishing each of the changes in physiological parameters associated with IDegLira revealed that the key drivers of improved clinical outcomes were reduced rates of minor hypoglycemia and improvements in BMI. Abolishing these differences between the treatment arms resulted in quality-adjusted life expectancy benefits of 0.20 and 0.22 QALYs, respectively. Applying only the statistically significant differences between the treatment arms resulted in an ICER of CZK 348,373 per QALY gained.

Applying an alternative $\mathrm{HbA}_{1 \mathrm{c}}$ progression with no increases applied at any stage of the analysis (attempting to replicate the legacy effect) resulted in improved incremental clinical outcomes and a smaller increase in costs, with the ICER falling to CZK 259,552 per QALY gained. Application of the UKPDS $\mathrm{HbA}_{1 \mathrm{c}}$ progression equation resulted in only small changes in the incremental differences between the treatment arms. These analyses show that the conclusions were robust to changes in assumptions around long-term changes in $\mathrm{HbA}_{1 \mathrm{c}}$.

Using the upper $95 \%$ confidence interval of the $\mathrm{HbA}_{1 \mathrm{c}}$ change in the IDegLira arm resulted in an increased clinical benefit, with the ICER falling to CZK 328,310 per QALY gained. Applying the lower 95\% confidence interval of the $\mathrm{HbA}_{1 \mathrm{c}}$ change in the IDegLira arm had the 


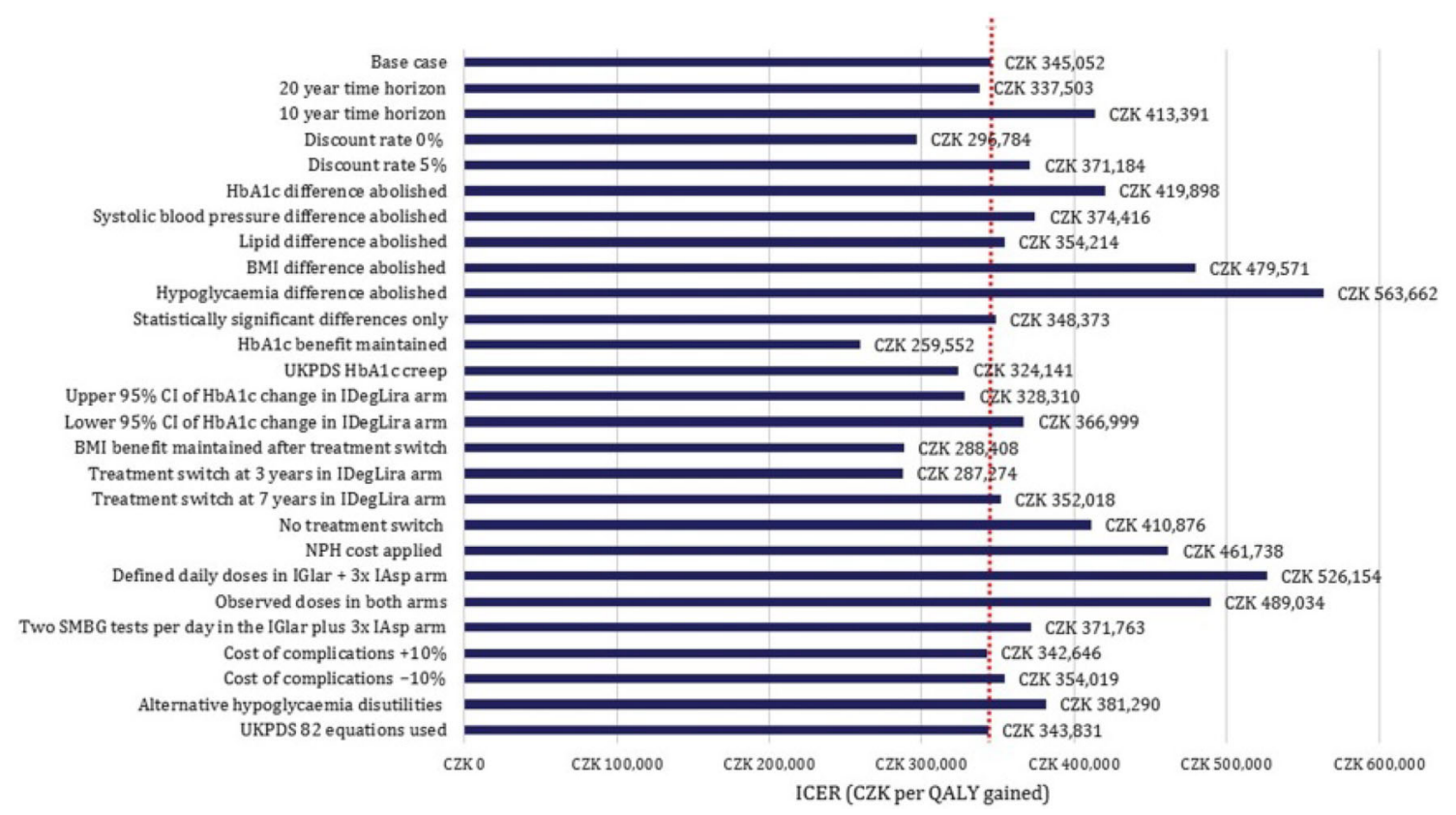

Fig. 2 IDegLira [fixed-ratio combination of the insulin analog degludec (IDeg) and the glucagon-like peptide-1 (GLP-1) receptor agonist (GLP-1 RA) liraglutide] versus basal-bolus therapy: sensitivity analysis results. Red dotted line shows the base case incremental cost-effectiveness ratio (ICER). The willingness-to-pay threshold in the Czech

converse effect, with the ICER increasing to CZK 366,999 per QALY gained.

Maintaining the BMI benefit associated with IDegLira after treatment switching resulted in an increased clinical benefit, with only a small change in costs. An ICER of CZK 288,408 per QALY gained was calculated.

Changing the assumptions around treatment switching had a notable impact on both incremental clinical and cost outcomes, but variation in ICERs was relatively small. Maintaining patients on IDegLira for a longer period of time increased the incremental clinical benefit but increased the additional cost, while shortening the treatment duration had the converse effect. Assuming no treatment switching resulted in an ICER of CZK 410,876 per QALY gained.

Applying the cost of NPH insulin in the IGlar $+3 \times$ IAsp arm lead to an increased ICER of CZK 461,738 per QALY gained. Applying defined daily doses or observed doses (i.e., not adjusted
Republic at the time of analysis was CZK 1,100,000 per QALY gained. BMI Body mass index, CI confidence interval, CZK Czech Koruna, $\mathrm{HbA}_{1 \mathrm{c}}$ glycated haemoglobin, IGlar $+3 \times$ IAsp, addition of insulin aspart to insulin glargine three times daily, NPH insulin intermediate-acting insulin, UKPDS 82 UK Prospective Diabetes Study

by the statistical model) resulted in an increased incremental cost difference, with increased ICERs. In the conservative analysis where patients receiving IGlar $+3 \times$ IAsp used only two needles and two SMBG tests per day the ICER increased to CZK 371,763 per QALY gained.

Increasing the cost of treatment of diabetes-related complications resulted in a reduced increase in costs with IDegLira, while reducing the cost of treatment of diabetes complications had the converse effect. In these two analyses the ICERs varied from the base case by approximately CZK 4000 per QALY gained.

Use of alternative hypoglycemia disutilities resulted in only a small change in the quality-adjusted life expectancy benefit with IDegLira and only a small change in the ICER. Similarly, using the updated UKPDS risk equations resulted in only a small change in the calculated ICER. 


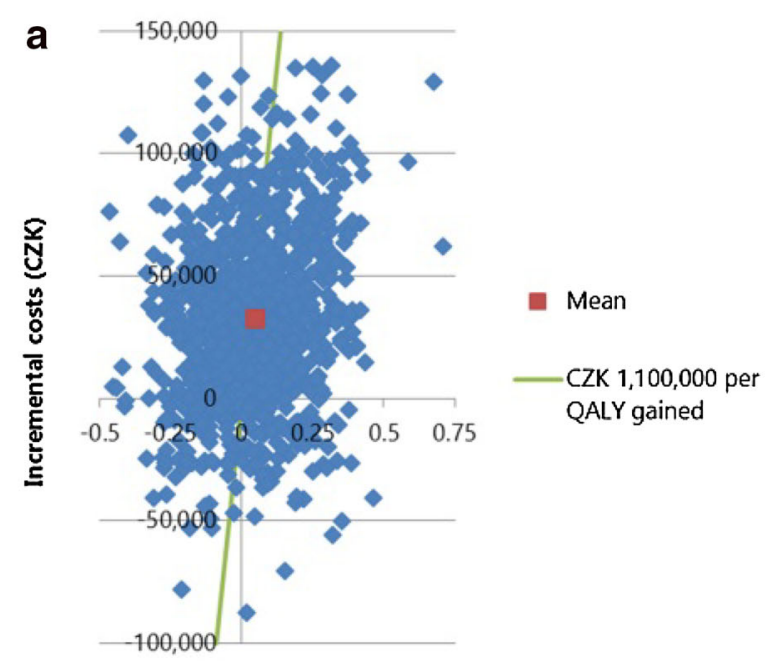

Incremental quality-adjusted life expectancy (QALYs)

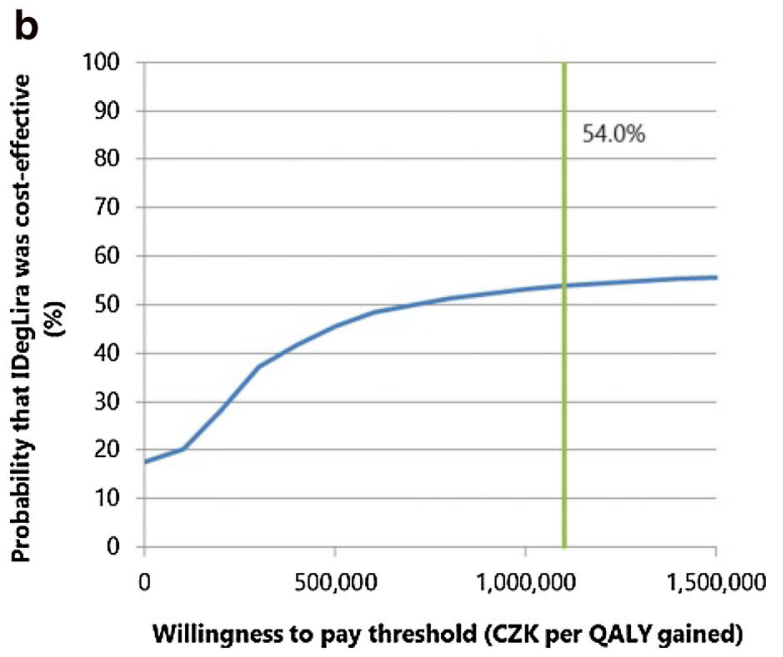

Fig. 3 Probabilistic sensitivity analysis for IDegLira versus basal-bolus therapy. a Cost-effectiveness scatterplot. b Cost-effectiveness acceptability curve

\section{Probabilistic Sensitivity Analysis Results}

The incremental cost-effectiveness scatterplot presents the incremental costs versus incremental effectiveness (QALYs gained) for IDegLira versus IGlar U100 + $3 \times$ IAsp (Fig. 3a) and shows 1000 mean values, each from a cohort of 1000 patients run through the model with sampling from distributions around model input parameters. The majority $(97.1 \%)$ of points fell in the upper right quadrant, revealing both increased effectiveness (i.e., incremental quality-adjusted life expectancy) and increased total costs for IDegLira compared with IGlar U100 + $3 \times$ IAsp.

The data from the scatterplot were used to generate a cost-effectiveness acceptability curve (Fig. 3b). Based on this analysis, assuming a WTP threshold of CZK 1,100,000 per QALY gained, the modeling analysis indicated that there was a $54.0 \%$ probability that IDegLira was cost-effective versus IGlar U100 plus $3 \times$ IAsp.

\section{Scenario Analysis-IDegLira vs Liraglutide added to Basal Insulin}

Treatment with IDegLira was associated with improvements in a quality-adjusted life expectancy of 0.05 QALYs, at an additional cost of CZK 33,231 over a patient's lifetime versus liraglutide added to basal insulin (Table 5). IDegLira was associated with an ICER of CZK 693,763 per QALY gained versus liraglutide added to basal insulin, which falls below the commonly quoted WTP threshold of CZK 1,100,000 per QALY gained; therefore, IDegLira is likely to be considered cost-effective.

Sensitivity analyses found that the outcomes projected in the present analysis were robust to changes in the majority of input parameters and the assumptions used (see ESM Appendix Table S4). IDegLira was likely to be cost-effective in most scenarios investigated, with ICERs falling under the WTP threshold of CZK 1,100,000 per QALY gained. The scenarios in which IDegLira was no longer cost-effective versus liraglutide added to basal insulin were when the time horizon was reduced to 10 years, the $\mathrm{HbA}_{1 \mathrm{c}}$ difference was abolished, defined daily doses were used for liraglutide added to basal insulin, and observed doses were used in both treatment arms. The parameter that had the largest impact on the ICER was abolishing the $\mathrm{HbA}_{1 \mathrm{c}}$ difference, identifying that the key driver of improved clinical outcomes with IDegLira versus liraglutide added to basal insulin was the greater reduction in $\mathrm{HbA}_{1 \mathrm{c}}$.

\section{DISCUSSION}

Results from this long-term economic evaluation suggest that, from a public payer 
Table 5 Base results for scenario analysis-IDegLira versus liraglutide added to basal insulin

\begin{tabular}{llll}
\hline Parameters & IDegLira & $\begin{array}{l}\text { Liraglutide added to basal } \\
\text { insulin }\end{array}$ & Difference \\
\hline Discounted life expectancy (years) & $13.56(0.19)$ & $13.51(0.19)$ & +0.05 \\
$\begin{array}{l}\text { Discounted quality-adjusted life expectancy } \\
\quad \text { QALYs) }\end{array}$ & $8.77(0.13)$ & $8.72(0.13)$ & +0.05 \\
Discounted direct costs (CZK) & $1,024,189$ & $990,958(25,453)$ & $+33,231$ \\
& $(26,092)$ & & \\
ICER (life expectancy) & CZK 642,771 per life year gained & \\
ICER (quality-adjusted life expectancy) & CZK 693,763 per QALY gained & \\
\hline
\end{tabular}

Values in table are presented as the mean with the SD in parenthesis

perspective in the Czech Republic, for patients with T2DM uncontrolled on basal insulin, IDegLira is likely to be cost-effective versus IGlar $\mathrm{U} 100+3 \times$ IAsp (basal-bolus therapy), with an ICER of CZK 345,052 per QALY gained. This falls well below the commonly accepted WTP threshold in the Czech Republic of CZK 1,100,000 per QALY gained.

IDegLira was associated with improved clinical outcomes versus IGlar $+3 \times$ IAsp. The key drivers of improved clinical outcomes in the IDegLira arm were reduced rates of hypoglycemia and reductions in BMI. Changes in these risk factors mainly affect the qualityrather than the duration-of life. However, reductions in $\mathrm{HbA}_{1 \mathrm{c}}$ and systolic blood pressure were also important in driving life expectancy benefits. These treatment differences resulted in a reduced incidence of diabetes-related complications and therefore impacted on the duration of life, quality of life, and direct costs. IDegLira was associated with increased mean direct costs compared with IGlar $+3 \times$ IAsp, driven by the higher annual cost of IDegLira versus IGlar + $3 \times$ IAsp over the first 5 years of the analysis. However, this increased direct cost was partially offset by cost savings through the lower need for treatment of diabetes-related complications as a result of improved treatment.

Sensitivity analyses found that the results were robust to changes in the input parameters and assumptions. All ICERs remained below the commonly quoted WTP threshold of CZK $1,100,000$ per QALY gained. The highest ICER identified was CZK 563,662 per QALY gained, when the difference in hypoglycemia rate was abolished.

This study was designed to capture the most appropriate comparator for patients failing to achieve glycemic control on basal insulin therapy in the Czech Republic. The most common therapeutic adaptation for such patients in the Czech Republic is the addition of fast-acting prandial insulin and, therefore, we considered IGlar U100 $+3 \times$ IAsp to be the most appropriate comparator in our analysis. However, the combination of GLP-1 RA and basal insulin is also included as an option in a recent guidance in the Czech Republic. Therefore, we also conducted a scenario analysis to evaluate the cost-effectiveness of IDegLira versus liraglutide added to basal insulin. In this latter scenario, IDegLira was associated with an ICER of CZK 693,763 per QALY gained, which also falls below the commonly quoted WTP threshold of CZK 1,100,000 per QALY gained, and thus likely to be considered cost-effective.

A potential limitation of the study was the reliance on relatively short-term clinical trial data to make long-term projections, a problem common to a number of health economic analyses. The uncertainty around making long-term projections from short-term data remains one of the essential principles of health economic modeling, and it remains arguably one of the best available options to inform decision-making in the absence of long-term clinical trial data. Every effort has been made in 
the present analysis to minimize any element of clinical doubt around the accuracy of such an approach, mainly by using an extensively published model of diabetes which has been validated against real-life data both on first publication and recently following a series of model updates $[28,38]$. Despite certain limitations, projecting outcomes over patient lifetimes is recommended in guidelines for economic evaluation of interventions for patients with diabetes mellitus [39].

In the absence of head-to-head clinical trials, data to inform these analyses were derived from an indirect statistical pooled analysis. The use of evidence synthesis, such as the indirect comparison, using robust methodologies is becoming an increasingly important and accepted method for health technology assessment globally [40]. The methodology used in the pooled analysis is recognized by the European Network for Health Technology Assessment (EUNETHTA) guidelines on how to conduct indirect analyses [41] and has been used previously [42].

The fixed ratio combination of IDegLira utilizes the complimentary mechanisms of action of a basal insulin and a GLP-1 RA to achieve glycemic control while mitigating the risk of hypoglycemia and avoiding weight gain. IDegLira may also be advantageous with regard to treatment adherence as it is associated with a lower incidence of gastrointestinal side effects, such as nausea, than is typically observed with GLP-1 RAs, a likely result of the gradual increase in the dose of the liraglutide component of IDegLira during dose titration [43]. The use of GLP-1 RAs has been associated with a risk of developing acute pancreatitis; however, a meta-analysis investigating the use of GLP-1 RAs and pancreatitis found that neither liraglutide nor exenatide were associated with an increased risk of acute pancreatitis [44], and there have been few reported events of pancreatitis with IDegLira [19]. The once-daily IDegLira treatment regimen means that patients have a simple treatment option with reduced treatment complexity, with up to three fewer daily injections than basal-bolus regimens. The combination of IDeg and liraglutide in a single pen device means that patients will only need to perform a single dose adjustment, and resource use costs (e.g. needles and SMBG testing) will be lower than with basal-bolus therapy.

\section{CONCLUSION}

In the Czech Republic, IDegLira is an attractive alternative treatment option for patients with T2DM uncontrolled on basal insulin. In particular, IDegLira is associated with a reduced risk of hypoglycemia and weight gain versus basal-bolus therapy [21, 22], both of which are common obstacles to treatment intensification [21].

\section{ACKNOWLEDGEMENTS}

This study and the processing charges of this article in Diabetes Therapy were funded by Novo Nordisk.

Barnaby Hunt performed the analysis and interpretation of results. Milan Kvapil, Martin Prázný, Pavel Holik and Karel Rychna were responsible for local adaptation of the analysis and its adherence to local guidelines. All authors contributed to study design, data collection, and interpretation of results.

All authors had full access to all of the data in this study and take complete responsibility for the integrity of the data and accuracy of the data analysis.

All named authors meet the International Committee of Medical Journal Editors (ICMJE) criteria for authorship for this manuscript, take responsibility for the integrity of the work as a whole, and have given final approval for the version to be published.

The authors acknowledge the assistance of Carrie Fidler at DRG Abacus (sponsored by Novo Nordisk) for medical writing and editorial support. Ossian received consulting fees from Novo Nordisk to support the analysis.

Disclosures. Pavel Holik is an employee of Novo Nordisk. Karel Rychna is an employee of Novo Nordisk. Barnaby Hunt is an employee of Ossian Health Economics and Communications. Martin Prázný and Milan Kvapil have nothing to disclose. 
Compliance with Ethics Guidelines. This article is based on previously conducted studies, and does not involve any new studies of human or animal subjects performed by any of the authors.

Data Availability. The datasets used and/or analyzed during the current study are available from the corresponding author on reasonable request.

Open Access. This article is distributed under the terms of the Creative Commons Attribution-NonCommercial 4.0 International License (http://creativecommons.org/licenses/ by-nc/4.0/), which permits any noncommercial use, distribution, and reproduction in any medium, provided you give appropriate credit to the original author(s) and the source, provide a link to the Creative Commons license, and indicate if changes were made.

\section{REFERENCES}

1. Campbell RK, Martin TM. The chronic burden of diabetes. Am J Manag Care. 2009;15:S248-54.

2. Institute of Health Information and Statistics of the Czech Republic (ÚZIS). Health Minister: brief overview of activity in the field of diabetology and endocrinology for the period 2007-2015. Available at: http://www.uzis.cz/publikace/zdravotnictvi-crstrucny-prehled-cinnosti-oboru-diabetologie-endokri nologie-za-obdobi-2007-2015. Accessed 21 Aug 2017.

3. Bagust A, Beale S. Deteriorating beta-cell function in type 2 diabetes: a long-term model. QJM. 2003;96:281-8.

4. Diabetes UK. Diabetes: facts and stats. 2014. Available at: http://www.diabetes.org.uk/Documents/ About\%20Us/Statistics/Diabetes-key-stats-guidelinesApril2014.pdf. Accessed 21 Aug 2017.

5. Dolezal T, Pisarikova Z, Bartaskova D. The cost of type 2 diabetes mellitus in Czech Republic. Value Health. 2008;11:PDB31 (abstract).

6. International Diabetes Federation (IDF). Diabetes atlas. 7th edn, 2015. Available at: http://www.idf. org/idf-diabetes-atlas-seventh-edition. Accessed 21 Aug 2017.
7. Inzucchi SE, Bergenstal RM, Buse JB, et al. Management of hyperglycemia in type 2 diabetes, 2015: a patient-centered approach: update to a position statement of the American Diabetes Association and the European Association for the Study of Diabetes. Diabetes Care. 2015;38:140-9.

8. Fonseca V. Defining and characterising the progression of type 2 diabetes. Br J Diabetes Vasc Dis. 2008;8:S3.

9. American Diabetes Association. Standards of medical care in diabetes-2017. Diabetes Care. 2017;40.

10. Czech Diabetes Society. Recommendations for teh care of patients with diabetes and its complications. Available at: http://www.diab.cz/en/introduction. Accessed 21 Aug 2017.

11. Dale J, Martin S, Gadsby R. Insulin initiation in primary care for patients with type 2 diabetes: $3--$ year follow-up study. Prim Care Diabetes. 2010;4:85-9.

12. Giugliano D, Maiorino MI, Bellastella G, Chiodini P, Ceriello A, Esposito K. Efficacy of insulin analogs in achieving the hemoglobin A1c target of $<7 \%$ in type 2 diabetes: meta-analysis of randomized controlled trials. Diabetes Care. 2011;34:510-7.

13. de Pablos-Velasco P, Parhofer KG, Bradley C, et al. Current level of glycaemic control and its associated factors in patients with type 2 diabetes across Europe: data from the PANORAMA study. Clin Endocrinol (Oxf). 2014;80:47-56.

14. Peyrot M, Barnett AH, Meneghini LF, Schumm-Draeger PM. Insulin adherence behaviours and barriers in the multinational global attitudes of patients and physicians in insulin therapy study. Diabet Med. 2012;29:682-9.

15. United Kingdom Prospective Diabetes Study (UKPDS). Intensive blood-glucose control with sulphonylureas or insulin compared with conventional treatment and risk of complications in patients with type 2 diabetes (UKPDS 33). UK Prospective Diabetes Study (UKPDS) Group. Lancet. 1998;352:837-53.

16. Home PD, Boulton AJM, Jimenez J, Landgraf R, Osterbrink B, Christiansen JS. Issues relating to the early or earlier use of insulin in type 2 diabetes. Pract Diabetes Int. 2003;20:63-71.

17. Inzucchi SE, Bergenstal RM, Buse JB, et al. Management of hyperglycemia in type 2 diabetes: a patient-centered approach: position statement of the American Diabetes Association (ADA) and the European Association for the Study of Diabetes (EASD). Diabetes Care. 2012;35:1364-79. 
18. Dushay J, Abrahamson MJ. Insulin therapy for type 2 diabetes: making it work. J Fam Pract. 2010;59:E1-8.

19. European Medicines Agency. Xultophy® (IDegLira) Summary of product characteristics. Available at: http://www.ema.europa.eu/docs/en_GB/document library/EPAR_-_Product_Information/human/002 647/WC500177657.pdf. Accessed 21 Aug 2017.

20. Buse JB, Vilsboll T, Thurman J, et al. Contribution of Liraglutide in the fixed-ratio combination of Insulin Degludec and Liraglutide (IDegLira). Diabetes Care. 2014;37:2926-33.

21. Lingvay I, Manghi FP, Garcia-Hernandez P, et al. Effect of insulin glargine up-titration vs insulin degludec/liraglutide on glycated hemoglobin levels in patients with uncontrolled type 2 diabetes: the DUAL $\mathrm{V}$ randomized clinical trial. JAMA. 2016;315:898-907.

22. Freemantle N, Mamdani M, Vilsboll T, Kongso JH, Kvist K, Bain SC. IDegLira versus alternative intensification strategies in patients with type 2 diabetes inadequately controlled on basal insulin therapy. Diabetes Ther. 2015;6:573-91.

23. Sassi F. Calculating QALYs, comparing QALY and DALY calculations. Health Policy Plan. 2006;21:402-8.

24. State Institute for Drug Control (SÚKL). http:// www.sukl.cz/. Accessed 21 Aug 2017.

25. State Institute for Drug Control (SÚKL). Reimbursement decision. http://www.sukl.eu/modules/ procedures/doc.php?id=167487234. Accessed 21 Aug 2017.

26. Hunt B, Glah D, van der Vliet M. Modeling the long-term cost-effectiveness of IDegLira in patients with type 2 diabetes who are failing to meet glycemic targets on basal insulin alone in The Netherlands. Diabetes Ther. 2017;8:753-65.

27. Hunt B, Mocarski M, Valentine WJ, Langer J. IDegLira versus insulin glargine U100: a long-term cost-effectiveness analysis in the US setting. Diabetes Ther. 2017;8:531-44.

28. McEwan P, Foos V, Palmer JL, Lamotte M, Lloyd A, Grant D. Validation of the IMS CORE diabetes model. Value Health. 2014;17:714-24.

29. Palmer AJ, Roze S, Valentine WJ, et al. The CORE Diabetes Model: projecting long-term clinical outcomes, costs and cost-effectiveness of interventions in diabetes mellitus (types 1 and 2) to support clinical and reimbursement decision-making. Curr Med Res Opin. 2004;20[Suppl 1]:S5-26.
30. World Health Organization. Life tables by country. Czech Republic. Available from: http://apps.who. int/gho/data/node.main.692. Accessed May 2015.

31. State Institute for Drug Control (SÚKL). Health economic guidance for the Czech Republic. http:// www.sukl.cz/file/85481_1_1. Accessed 21 Aug 2017.

32. Sovinova H, Csemy L. The use of tobacco and alcohol in the Czech Republic 2012. National Institute of Public Health, 2013. http://www.szu.cz/ uploads/documents/czzp/zavislosti/TabAlkoAngl. pdf. Accessed May 2015.

33. Bagust A, Beale S. Modelling EuroQol health-related utility values for diabetic complications from CODE-2 data. Health Econ. 2005;14:217-30.

34. Clarke P, Gray A, Holman R. Estimating utility values for health states of type 2 diabetic patients using the EQ-5D (UKPDS 62). Med Decis Making. 2002;22:340-9.

35. Evans M, Khunti K, Mamdani M, et al. Health-related quality of life associated with daytime and nocturnal hypoglycaemic events: a time trade-off survey in five countries. Health Qual Life Outcomes. 2013;11:90.

36. Tengs TO, Wallace A. One thousand health-related quality-of-life estimates. Med Care. 2000;38:583-637.

37. Currie CJ, Morgan CL, Poole CD, Sharplin P, Lammert M, McEwan P. Multivariate models of health-related utility and the fear of hypoglycaemia in people with diabetes. Curr Med Res Opin. 2006;22:1523-34.

38. Palmer AJ, Roze S, Valentine WJ, et al. Validation of the CORE Diabetes Model against epidemiological and clinical studies. Curr Med Res Opin. 2004;20(Suppl 1):S27-40.

39. American Diabetes Association Consensus Panel. Guidelines for computer modeling of diabetes and its complications. Diabetes Care. 2004;27:2262-5.

40. Dias SW, N.J.; Sutton, A.J.; Ades, A.E. NICE DSU Technical Support Document 1: Introduction to evidence synthesis for decision making, 2011; last updated April 2012. http://www.nicedsu.org.uk/ TSD1\%20Introduction.final.08.05.12.pdf. Accessed 21 Aug 2017.

41. European Network for Health Technology Assessment (EUNETHTA). Guideline-comparators and comparisons: direct and indirect comparisons. February 2013. https://5026.fedimbo.belgium.be/ sites/5026.fedimbo.belgium.be/files/Direct\%20and\% 20indirect\%20comparisons.pdf. Accessed 21 Aug 2017. 
42. Zinman B, Schmidt WE, Moses A, Lund N, Gough S. Achieving a clinically relevant composite outcome of an $\mathrm{HbA1c}$ of $<7 \%$ without weight gain or hypoglycaemia in type 2 diabetes: a meta-analysis of the liraglutide clinical trial programme. Diabetes Obes Metab. 2012;14:77-82.

43. Aroda V, Jaeckel E, Jarlov H, Abrahamsen T, Vilsbøll $\mathrm{T}$. Incidence of gastrointestinal side effects similar between IDegLira and non-GLP-1 RA comparators.
Presented at American Diabetes Association (ADA 2015) 75th Scientific Sessions, June 5-9, Boston, MA, p 1009.

44. Alves C, Batel-Marques F, Macedo AF. A meta-analysis of serious adverse events reported with exenatide and liraglutide: acute pancreatitis and cancer. Diabetes Res Clin Pract. 2012;98:271-84. 